\title{
DETERMINANTS OF RECURRENCE RATE DURING MIDTERM FOLLOW-UP OF PATIENTS AFTER ENDOVENOUS LASER ABLATION OF PRIMARY LOWER LIMB VARICOSE VEINS
}

\author{
Mohammed Hatem $^{1}$, Mahmoud Sobhy ${ }^{1}$, Wageh Fawzy ${ }^{1}$, Karem Sabry ${ }^{1}$, and \\ Ahmed Al-Taher ${ }^{2}$
}

\begin{abstract}
1: Departments of vascular surgery, and 2: Department of diagnostic and interventional radiology, Ain shams University.

Corresponding Author:

Mohammed Hatem Abdel Azim

Mobile: +2 01002616811

E-mail:

dukebalousa@gmail.com
\end{abstract}

Received : 30/4/2020

Accepted: $27 / 5 / 2020$

Online ISSN: 2735-3540

\begin{abstract}
:
Background: The goal of this prospective cohort study was to study the different determinants impacting primary varicose vein recurrence rates and patterns after endo venous laser ablation (EVLA) for primary lower limb varicose veins.
\end{abstract}

Patients and Methods: 127 symptomatic patients (127 limbs) with great saphenous vein reflux ( $>0.5$ seconds), GSV diameter $>3 \mathrm{~mm}$ and pre-operative incompetent perforators were followed up within two years for recurrence after EVLA.

Outcomes: Recurrence was defined clinically by venous clinical severity score (VCSS) and CEAP classification and radiologically by patterns of reflux on duplex ultrasound examination. Assessment was done at 1, 6, 12 and 24 months after the procedure.

Results: Two-year life table analysis showed varicose vein recurrence in $9(7.1 \%)$ of

limbs. Varicose vein recurrence was mostly seen owed to due to BMI more than $30.5 \mathrm{~kg} / \mathrm{m}^{2}$ in $77.8 \%$ ( $p<0.001,95 \%$ CI 1.105 to 1.590) of recurrence patients, refluxing anterior accessory saphenous vein in $77.8 \%$ of patients ( $p<0.001,95 \%$ CI 3.2 to 1669.1) and postoperative incompetent perforators in $77.8 \%$ of patients $(p<0.001$, 95\% CI 2.7 to 69.3). Age, gender and pre-operative GSV diameter $\geq 5.5 \mathrm{~mm}$ were statistically insignificant in determination of recurrence.

Conclusion: BMI, refluxing anterior accessory saphenous vein and postoperative incompetent perforators are the most important determinants of recurrence after EVLA with a statistically significant impact in comparison with age, gender and preoperative dilated GSV diameter $\simeq 5.5 \mathrm{~mm}$.

Keywords: EVLA: Endovenous laser Ablation, AASV: Anterior Accessory Saphenous Vein, GSV: Great Saphenous Vein, VV: Varicose Veins, BMI: Body mass index, ROC: Receiver-operating characteristic curve.

\section{INTRODUCTION}

Chronic venous disease (CVD) is one of the most common pathologies in the general population of adults in both industrialized and developing countries ${ }^{[1]}$.
Superficial venous incompetence is a common disorder affecting $25 \%$ of women and $15 \%$ of men presenting with varicose veins. Venous insufficiency increases with age and is most commonly caused by primary valvular incompetence. The most important 
factors appear to be heredity, female sex, and previous phlebitis, pregnancy, obesity and use of OCPs, deep venous reflux ${ }^{[2]}$.

In 1999, Boné first reported on delivery of endoluminal laser energy into GSV with success $^{[3]}$.

Endovenous laser treatment which received approval from the US Food and Drug Administration in January 2002 allows delivery of laser energy directly into the blood vessel lumen. Enough heating of the vein wall is necessary to cause collagen contraction and denudation of endothelium ${ }^{[4]}$.

This technique works by using a range of different wavelengths to target different depths and diameters of vessels. Acting as a chromophore, hemoglobin within red blood cells of the target vein absorbs and converts the light to thermal energy which causes vessel destruction ${ }^{[5]}$.

Current guidelines have replaced conventional surgery by endovenous laser ablation (EVLA) and other endovenous thermal ablation (EVTA) techniques as the treatment of choice for incompetent saphenous veins and rendered them more effective with a reported success rate of approximately $90 \%$ in the previous studies ${ }^{[6]}$.

Studies showed that Neovascularization has been reported more frequently following surgery than after endovenous procedures. On the other hand, recanalization was reported more with EVLA than after surgery ${ }^{[7]}$.

Optimum prevention of recanalization and refluxing in a previously ablated GSV is tailored to the identification and addressing the potential risk factors: higher VCSS score, GSV diameter, sapheno femoral junction reflux, length of ablated vein, type of device \& BMI has all been reported to increase risk of Recurrence ${ }^{[8]}$.

\section{PATIENTS AND METHODS:}

This is a prospective nonrandomized cohort study which is a single arm clinical study to assess the determinants of recurrence rate including demographic and radiological data of patients after endovenous laser treatment of patients with primary varicose veins within 2 years postoperatively.

127 patients were selected for this prospective cohort after assessing the sample size using PASS $^{\circledR}$ version 11 program, setting the type- 1 error $(\alpha)$ at 0.05 and power at $80 \%$.

Criteria for selection included all symptomatic patients with Primary varicose veins caused by SFJ incompetence with GSV reflux ( $>0.5$ seconds) on Valsalva, multiple incompetent perforators (midthigh, below knee, above knee and ankle perforators), diameter $>3 \mathrm{~mm}$, as demonstrated by duplex US imaging and age up to 65 years.

While Patients with Nonpalpable pedal pulses $(\mathrm{ABI}<0.9)$, major co-morbities (ASA $>3$ ), bleeding disorders, old or recent deep vein thrombosis with or without recanalization as well as patients showing extremely tortuous GSV or superficial venous thrombosis or vein greater than $12 \mathrm{~mm}$ in diameter on duplex U/S were excluded.

Patients who met the criteria were evaluated for symptomatic venous disease. Of the 127 patients, $73 \%$ of this number had been operated on by the participating surgeons in this study.

Laser ablation was performed via target linear endovenous energy density (LEED) of $80-100 \mathrm{~J} / \mathrm{cm}$ using 1470-nm, continuousmode diode laser via a $600-\mu \mathrm{m}$ bare-tip fiber pullback of $1 \mathrm{~cm} / 10$ seconds.

The Primary end point of the study was based on "Recommended reporting standards for endovenous ablation for the treatment of venous insufficiency in 2007 which was defined as a clinical outcome of importance to patients (relief of the dominant presenting symptom, venous ulcer healing, prevention of progression of chronic venous insufficiency or a combination of these outcomes) in addition 
to anatomic success defined as successful ablation of the target vein, as demonstrated by complete lack of flow or disappearance of vein by duplex ultrasound imaging in the entire treated GSV ${ }^{[9]}$.

After completing the study tool, the form was reviewed for accuracy and resulting data were given a numerical value. The data was entered the Statistical Package IBMC SPSSC Statistics version 26 (IBMC) Corp., Armonk, NY) for statistical analysis.

Data was entered into 8 categories for each patient in the study: BMI, preoperative dilated GSV diameter $\geq 5.5 \mathrm{~mm}$, post- operative residual incompetent perforators, preoperative accessory saphenous vein, age, gender, pattern and time to recurrence were documented.

Patients were followed up for recurrence at 1, 6, 12 and 24 months which included re-evaluation of CEAP classifycation (Table 1), Venous Extremity Severity Score(Table 2) in addition to duplex scanning of treated limb in the standing position seeking for reflux(>0.5), partial or total occlusion of a segment or whole GSV(diagram 1), patency of deep venous system, presence of incompetent perforators, presence of accessory saphenous vein.
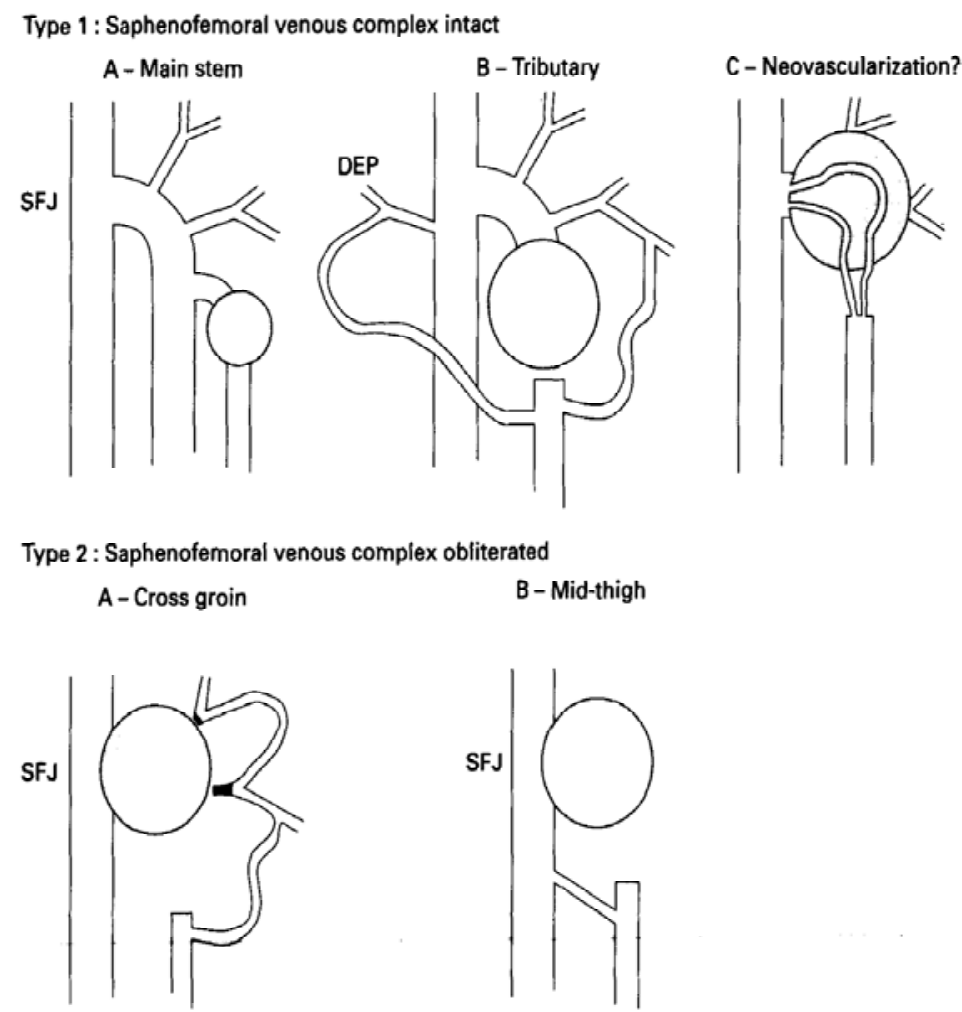

Diagram 1: Anatomical patterns of recurrent varicose veins in the groin. SFJ, saphenofemoral junction; DEP, deep external pudendal vein; $\mathrm{O}$, scar tissue. Type 1 recurrences were those in which there was some residual connection between the superficial and deep systems at or immediately around the saphenofemoral junction, requiring re-exploration. These were further subdivided by the nature of the connection into three subgroups as shown above. Type 2 recurrences were those in which there was no such connection; the recurrence arose either across the groin (i.e. derived from branches of the internal iliac vein or abdominal wall veins) or from thigh perforators. ${ }^{[12]}$ 
Table 1: CEAP classification for chronic venous disorders developed in 1994 as a descriptive classification and incorporated into "Reporting standards" in venous diseases ${ }^{[10]}$.

\begin{tabular}{|l|l|}
\hline $\mathrm{C} 0$ & No visible or palpable signs of venous disease \\
\hline $\mathrm{C} 1$ & Telangiectases, reticular veins, malleolar flare \\
\hline $\mathrm{C} 2$ & Varicose veins $(>3 \mathrm{~mm})$ \\
\hline $\mathrm{C} 3$ & Edema without skin changes \\
\hline $\mathrm{C} 4 \mathrm{a}$ & Pigmentation or eczema \\
\hline $\mathrm{C} 4 \mathrm{~b}$ & Lipodermatosclerosis or atrophie blanche \\
\hline $\mathrm{C} 5$ & Skin changes as defined above with healed ulceration \\
\hline $\mathrm{C} 6$ & Skin changes as defined above with active ulceration \\
\hline
\end{tabular}

Table 2: venous clinical severity scores (VCSS)

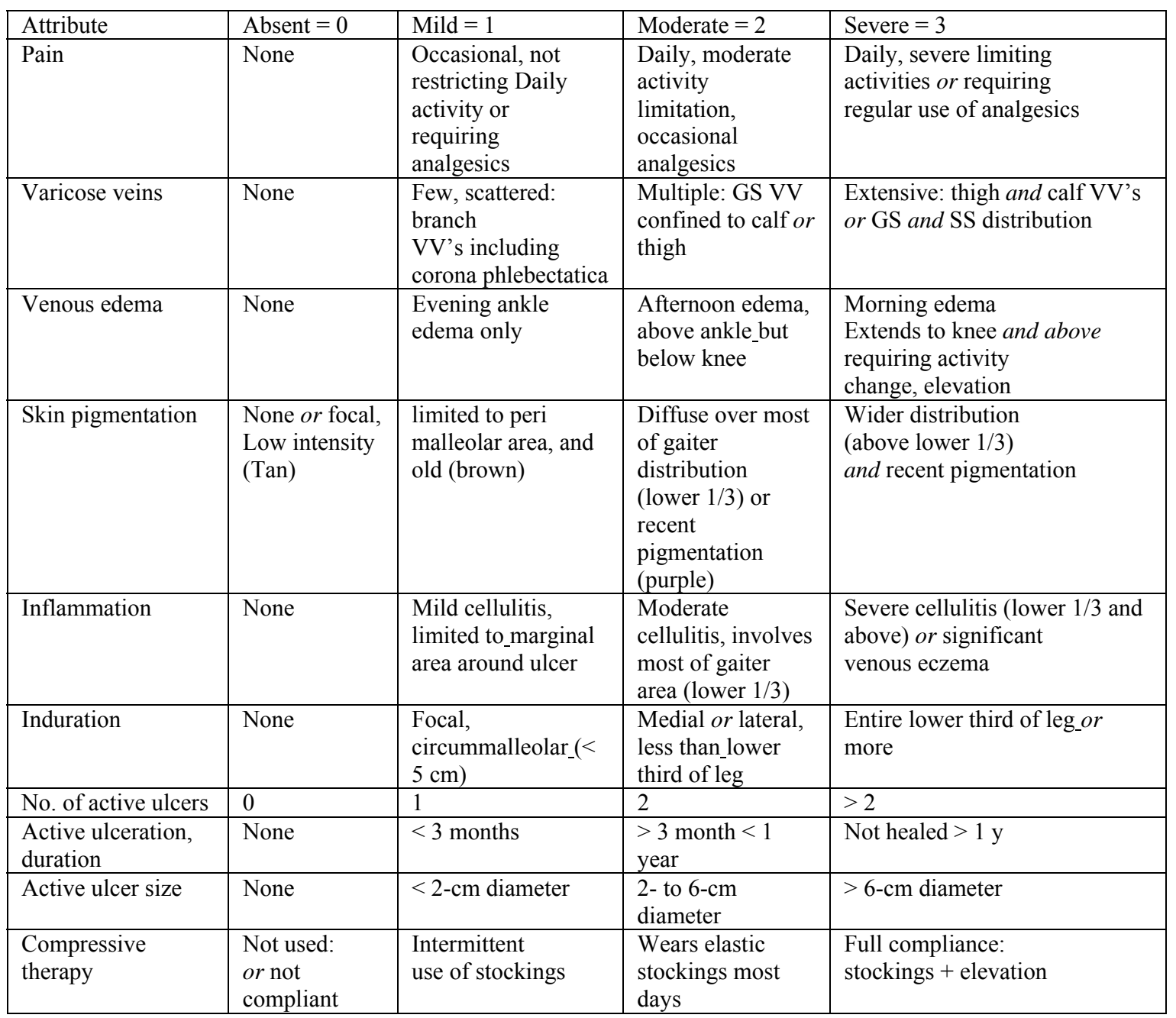

The VCSS includes 9 hallmarks of venous disease, each scored on a severity scale from 0 to 3. Compression therapy was added to scoring system with higher scores representing greater compliance. Absence of venous disease if score $\leq 3$ and score $\geq 8$ denotes severe disease ${ }^{[11]}$.

\section{RESULTS:}

Of the 127 patients entered into the study, 45 patients were females $(35.4 \%)$ and 82 patients were males $(64.6 \%)$. The mean age was $41 \pm 12$ years (21-65). Patients had mean BMI $29.3 \mathrm{~kg} / \mathrm{m}^{2} \pm 4.5(21-42)$. GSV was dilated $(\geq 5.5 \mathrm{~mm})$ in $79(62.2 \%)$ patients (table 3). 
Determinants of Recurrence Rate During Midterm Follow-Up of Patients After Endovenous Laser..

Table (3): Characteristics of the whole study population

\begin{tabular}{|l|c|}
\hline \multicolumn{1}{|c|}{ Variable } & Value \\
\hline Sex & \\
\hline$F$ & $45(35.4 \%)$ \\
\hline$M$ & $82(64.6 \%)$ \\
\hline Age (years) & $41 \pm 12(21-65)$ \\
\hline BMI $\left(\mathrm{kg} / \mathrm{m}^{2}\right)$ & $29.3 \pm 4.5(21-42)$ \\
\hline Preoperative dilated GSV (more than 5.5 mm) & $79(62.2 \%)$ \\
\hline Patent refluxing Anterior Accessory SV & $7(5.5 \%)$ \\
\hline Partial recanalization of GSV & $6(4.72 \%)$ \\
\hline Non-truncal varicosities(neovascularization) & $5(3.93 \%)$ \\
\hline Postoperative incompetent perforators & $29(23.2 \%)$ \\
\hline Recurrence & $9(7.1 \%)$ \\
\hline
\end{tabular}

Data are number $(\%)$ or mean \pm SD and range.

Recurrence occurred in 9 limbs (7.1\%) during the two-year follow-up (diagram 2)

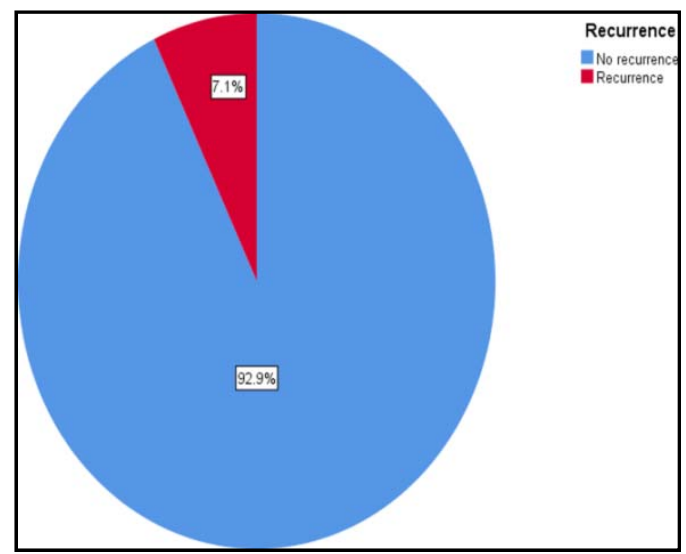

Diagram (2): Recurrence rate in the study population.

In our population study, pain was the $41 \%$, active venous ulcer in $7 \%$, skin chief presenting symptom in $42 \%$ of total pigmentation in $4 \%$ and leg edema in $6 \%$. number of patients, visible varicose veins in (diagram 3).

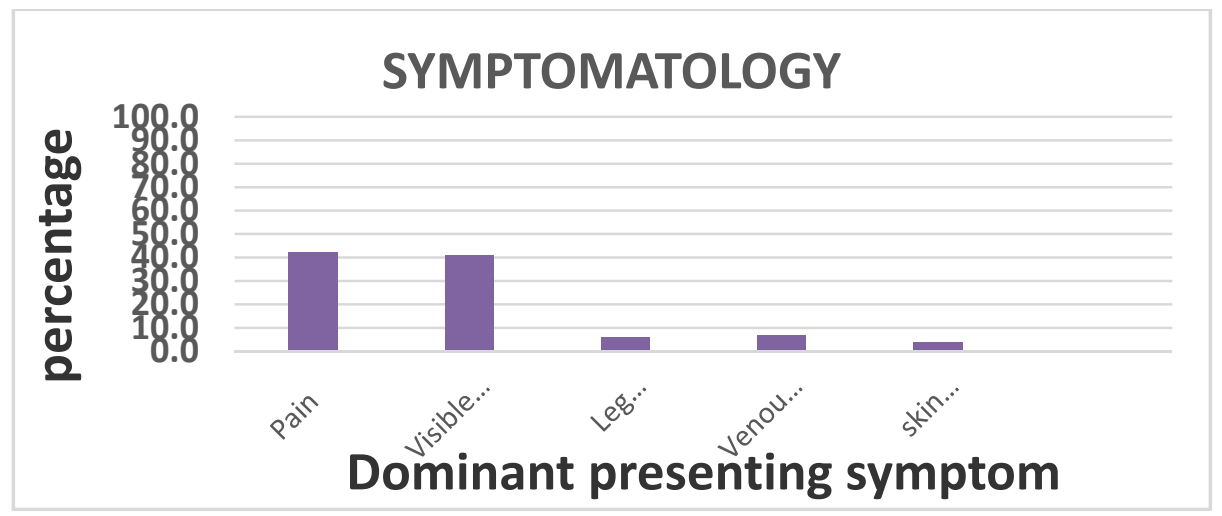

Diagram (3): Bar chart showing the main symptoms in the studied patients

The primary endpoint was reached in $92.9 \%$ of patients during the two-year follow-up. No progression of CVI according to VCSS and CEAP classification was noted in all non-recurrent patients. 7 patients had complete ulcer healing. Pain as the dominant symptom was improved in 50 patients. Venous edema became less significant in 7 
patients. Skin pigmentation became limited in 5 patients. Varicose veins disappeared in 49 patients. Complete lack of flow in GSV was seen in all non-recurrent patients. (table 4)

Table (4): Primary end point in non-recurrent patients

\begin{tabular}{|c|c|}
\hline Primary endpoint & Number of patients \\
\hline Complete ulcer healing & 7 \\
\hline Pain improvement & 50 \\
\hline Venous edema(C3) & 7 \\
\hline Skin pigmentation & 5 \\
\hline VV disappearance & 49 \\
\hline Complete GSV occlusion & 118 \\
\hline
\end{tabular}

Of the recurrent patients, 2 were females $(22.2 \%)$ while 7 were males $(77.8 \%)$. The mean age of recurrence was 44.9 years \pm 8.4 compared to 41.1 years \pm 12.2 in the non-recurrent group. The mean BMI was $34.1 \mathrm{~kg} / \mathrm{m}^{2} \pm 5.3(\mathrm{P}=0.001)$ in the recurrent group compared to $28.9 \pm 4.2$ in the non-recurrent group. Age, sex and preoperative GSV diameter $(\geq 5.5 \mathrm{~mm})$ were not statistically significant in both groups $(\mathrm{P}=0.152)$ (table 5).

7 of the 9 recurrent patients $(77.8 \%)$ had patent refluxing anterior accessory saphenous vein $(\mathrm{P}<0.001)$ and 7 of them
(77.8\%) had postoperative residual incompetent perforators $(\mathrm{P}<0.001)$.

Recurrence patterns included 5 patients (55.6\%) with non-truncal tributaries: 3(33.3\%) of them had incompetent perforators and 4(44.4\%) of them had patent AASV (table 5).

6 patients $(66.6 \%)$ showed partial recanalization of GSV: 5(55.6\%) of them had incompetent perforators and 5(55.6\%) of them had patent $A A S V$ (table 5).

No anterior accessory saphenous vein was found and only 22 patients (19\%) had postoperative incompetent perforators in the non-recurrent group (table 5).

Table (5): Comparison of patients who suffered or did not suffer recurrence

\begin{tabular}{|c|c|c|c|}
\hline Variable & $\begin{array}{l}\text { No recurrence } \\
\quad(n=118)\end{array}$ & $\begin{array}{l}\text { Recurrence } \\
(n=9)\end{array}$ & P-value* \\
\hline Sex & & & 0.490 \\
\hline$F$ & $43(36.4 \%)$ & $2(22.2 \%)$ & \\
\hline$M$ & $75(63.6 \%)$ & $7(77.8 \%)$ & \\
\hline Age (years) & $41.1 \pm 12.2$ & $44.9 \pm 8.4$ & $0.365 \S$ \\
\hline BMI $\left(\mathrm{kg} / \mathrm{m}^{2}\right)$ & $28.9 \pm 4.2$ & $34.1 \pm 5.3$ & $0.001 \S$ \\
\hline Preoperative dilated GSV & $71(60.2 \%)$ & $8(88.9 \%)$ & 0.152 \\
\hline Accessory SV & $0(0.0 \%)$ & $7(77.8 \%)$ & $<0.001$ \\
\hline Postoperative incompetent perforators & $22(19.0 \%)$ & $7(77.8 \%)$ & $<0.001$ \\
\hline Partial recanalization of GSV & $0(0.0 \%)$ & $6(66.7 \%)$ & $<0.001$ \\
\hline Non truncal varicosities (neovascularization) & $0(0.0 \%)$ & $5(55.6 \%)$ & $<0.001$ \\
\hline $\begin{array}{l}\text { Postoperative incompetent perforators+ Partial } \\
\text { recanalization of GSV }\end{array}$ & $0(0.0 \%)$ & $5(55.6 \%)$ & $<0.001$ \\
\hline Accessory SV+ Partial recanalization of GSV & $0(0.0 \%)$ & $5(55.6 \%)$ & $<0.001$ \\
\hline $\begin{array}{l}\text { Postoperative incompetent perforators }+ \text { Non truncal } \\
\text { varicosities }\end{array}$ & $0(0.0 \%)$ & $3(33.3 \%)$ & $<0.001$ \\
\hline Accessory SV+ Non truncal varicosities & $0(0.0 \%)$ & $4(44.4 \%)$ & $<0.001$ \\
\hline
\end{tabular}

Data are number $(\%)$ or mean \pm SD. *Fisher's exact test unless otherwise indicated.

§Unpaired t-test. 
BMI, accessory SV and postoperative incompetent perforators were compared in both recurrent and non-recurrent patients and were found to be statistically significant in determination of recurrence (diagrams 4,5,6).

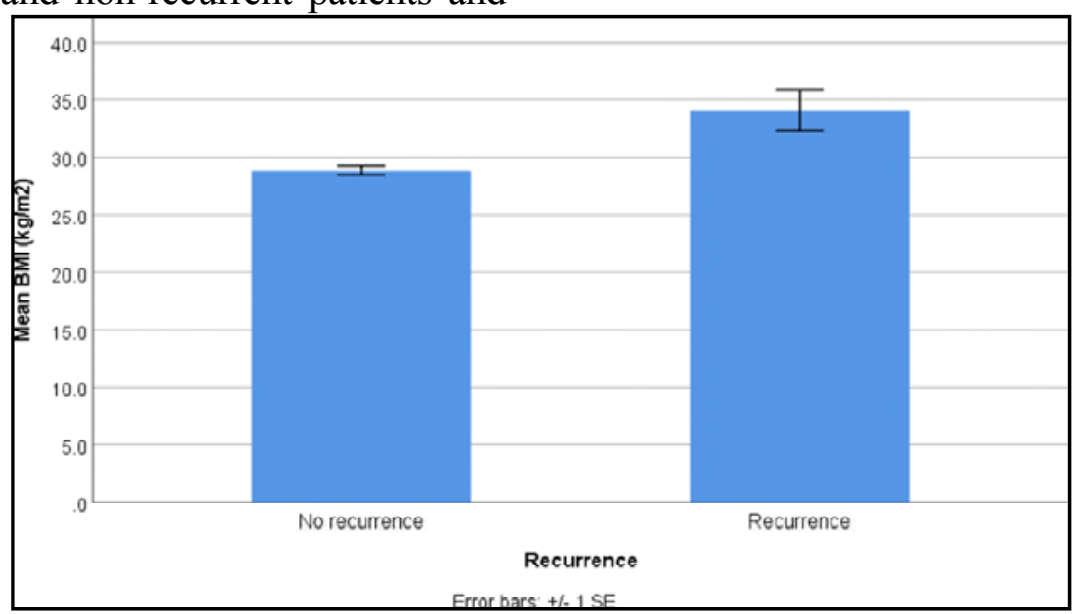

Diagram (4): Mean BMI in patients with or without recurrence. Error bars represent the standard error (SE).

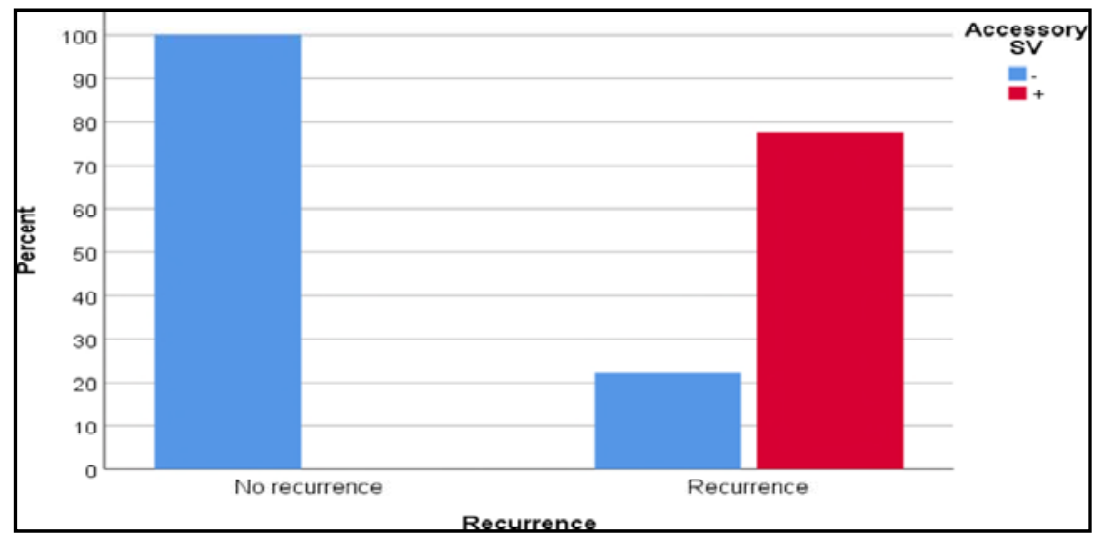

Diagram (5): Percentage of patients with accessory SV among those who suffered or did not suffer recurrence.

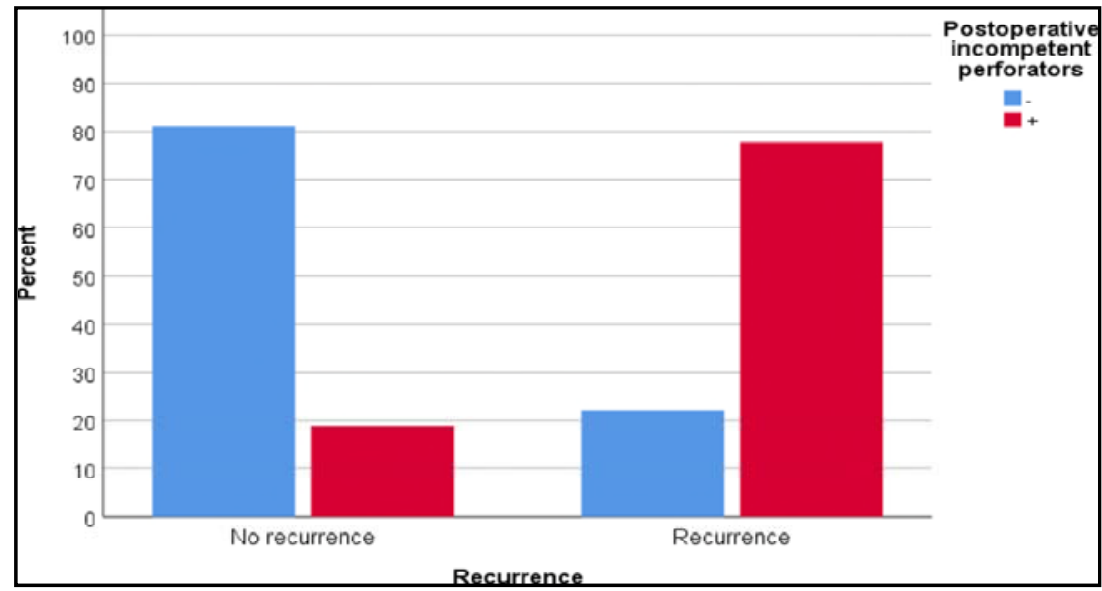

Diagram (6): Percentage of patients with postoperative incompetent perforators among those who suffered or did not suffer recurrence. 
The median time to recurrence in patients with accessory saphenous vein was 12 months but it could not be determined in patients without accessory saphenous vein. Difference between both Kaplan-Meier curves is statistically significant (hazard ratio $=73.1,95 \%$ CI 3.2 to 1669.1 , MantelCox log-rank chi-squared $=116.080, \mathrm{df}=1$, P-value $<0.001)$ (diagram 7).

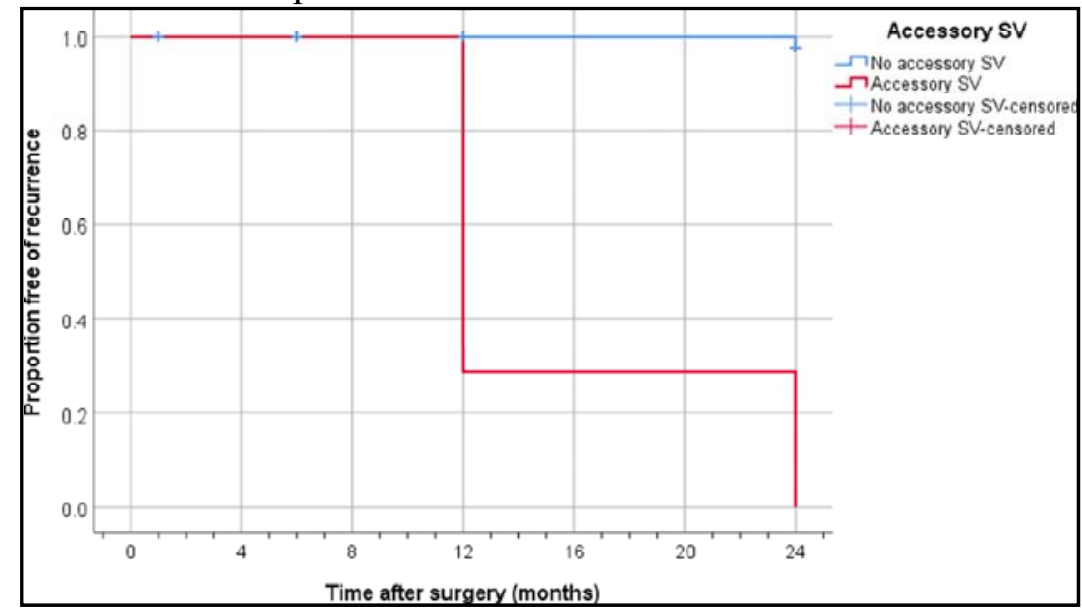

Diagram (7): Kaplan-Meier curves for the time to recurrence in patients with or without accessory SV.

The median time to recurrence in patients with or without postoperative incompetent perforators could not be determined in either group. However, difference between both Kaplan-Meier curves is statistically significant (hazard ratio $=13.7,95 \%$ CI 2.7 to 69.3 , MantelCox log-rank chi-squared $=18.983$, df $=1$, P-value $<0.001)($ diagram 8$)$

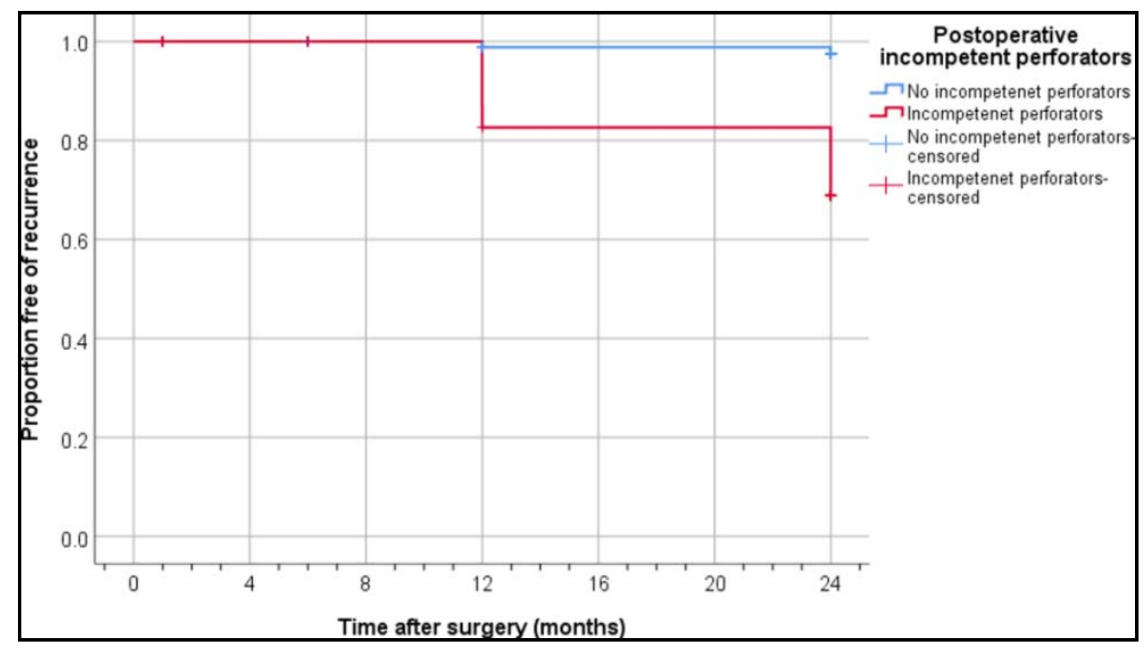

Diagram (8): Kaplan-Meier curves for the time to recurrence in patients with or without postoperative incompetent perforators.

BMI, accessory SV and postoperative incompetent perforators were selected based on statistically significant relation to recurrence by further bivariate analysis. Of these variables, BMI was the only independent predictor for recurrence that is retained by backward binary logistic regression (odds ratio $=1.325,95 \% \mathrm{CI}=$ 1.105 to $1.590, \mathrm{P}$-value $=0.002)($ table 6$)$. 
Determinants of Recurrence Rate During Midterm Follow-Up of Patients After Endovenous Laser..

Table (6): Results of backward binary logistic regression analysis for prediction of recurrence.

\begin{tabular}{|c|c|c|c|c|c|c|}
\hline Variable $^{*}$ & $\boldsymbol{B}$ & SE & Wald & P-value & Odds ratio & 95\% CI \\
\hline BMI $\left(\mathrm{kg} / \mathrm{m}^{2}\right)$ & 0.282 & 0.093 & 9.182 & $\mathbf{0 . 0 0 2}$ & 1.325 & 1.105 to 1.590 \\
\hline Constant & -11.437 & 3.115 & 13.479 & $<0.001$ & & \\
\hline
\end{tabular}

$\mathrm{B}=$ regression coefficient, Wald $=$ Wald statistic, $95 \% \mathrm{CI}=95 \%$ confidence interval.

*Variables removed by backward regression: Accessory SV and Postoperative incompetent perforators.

BMI has fair to good predictive value for recurrence with an area under the ROC curve (AUC) of $0.766(95 \% \mathrm{CI}=0.605-$ 0.926 , P-value $=0.001)$. Best cutoff is a

BMI $>30.5 \mathrm{~kg} / \mathrm{m}^{2}$ (sensitivity $=77.8 \%$, specificity $=61.0 \%, \quad \mathrm{~J}$-index $=0.388)$ (diagram 9).

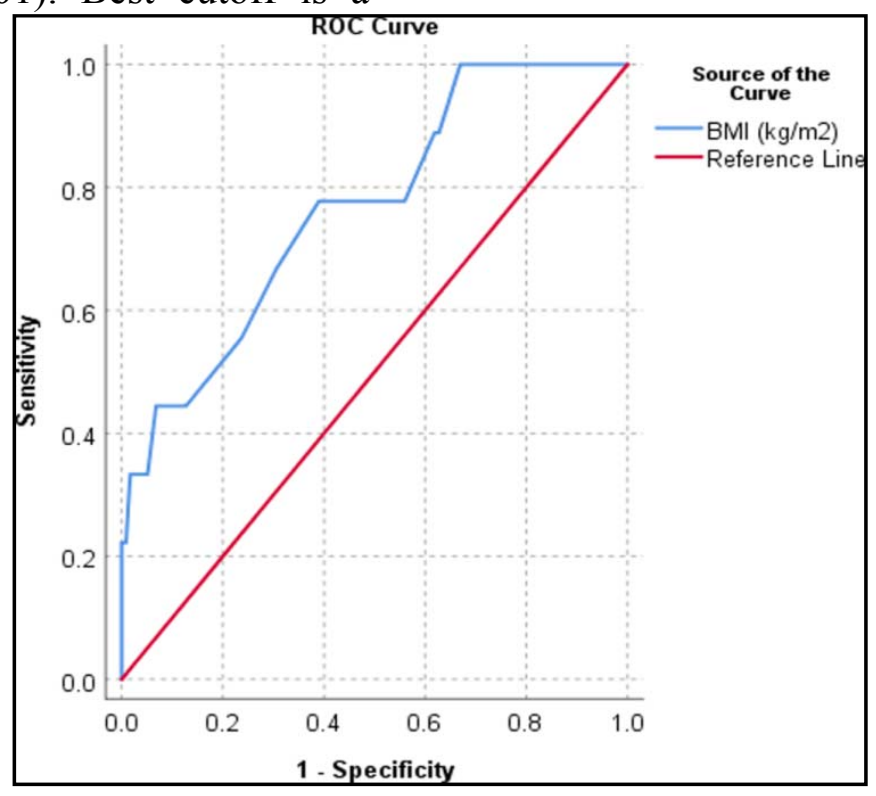

Diagram (9): Receiver-operating characteristic (ROC) curve for prediction of recurrence using BMI.

\section{DISCUSSION:}

Lower limb venous incompetence is an extremely important issue impacting lifestyle and morbidity of patients affecting up to $23 \%$ of adults and a striking incidence of $15 \%$ in male and $25 \%$ females. Great saphenous vein insufficiency contributes to most of the venous incompetence ${ }^{[13] .}$

Although EVLA is considered the optimal treatment modality for primary varicose veins in terms of providing secure ablation and declined recurrence rates, determinants impacting the rate of recurrence following this intervention is still not yet thoroughly studied in the previous literature.
Recurrence after EVLA can be defined by a duplex $\mathrm{u} / \mathrm{s}$ finding of recanalization either partial or total for the previously ablated great saphenous vein, or reemergence of varicosities at the same site of the great saphenous vein which could be due to neovascularization or non-avulsion of the thigh and calf perforators. Relapse or progression of CEAP classification or VCSS correlates to clinical recurrence ${ }^{[14]}$.

Age, Gender, BMI, pre-operative dilated GSV ( $\geq 5.5 \mathrm{~mm})$, preoperative AASV and postoperative incompetent perforators were the major determinants studied in each patient. Age and Gender were found to be statistically insignificant in our study. On the contrary, two prospective studies considered sex as a predictor of recanalization, but this 
was not confirmed in multivariable analysis [15],[16]. In addition, a metanalysis systematic review of 15 trials by Vander der Velden found that male gender is an independent predictor of GSV recanalization after EVLA ${ }^{83}$.Although no evidence was found in the literature to explain the male predominance in risk of recanalization, it could be hypothesized that the vein wall of males is thicker than the vein wall of females.

Although pre-operative dilated GSV $(\geq 5.5 \mathrm{~mm}$ ) was seen $88.6 \%$ of recurrent patients compared to $66.7 \%$ of non-recurrent patients in our study, it was found to be statistically insignificant. This was contradicted by the results of a recent study in 2019 by Kemaloğlu C which concluded that GSV diameter may predict the risk of early recanalization after the EVLA of the GSV especially if the diameter $>10 \mathrm{~mm}$.) [17]. It became a controversial issue to treat patients with very large GSV diameter $>12$ $\mathrm{mm}$ ) using EVLA. Some studies have found no influence of truncal vein size on outcomes but a pooled analysis of GSV recanalization in 15 studies in 2016 found vein diameter to be a strong predictor of recanalization one year after endothermal ablation ${ }^{[8]}$. Another study by Desmyttere $\mathrm{J}$ et al., found that recurrence was observed when the GSV trunk diameter $>8 \mathrm{~mm}$. One can hypothesize that blood remaining inside the lumen could absorb the laser light energy, limiting consequently the light transmitted to the vessel wall ${ }^{[18]}$. Fernández et al also found that GSV diameter $\geq 8.5 \mathrm{~mm}$ is an independent risk factor for recanalization [16]. As we used standard LEED for above knee GSV segment (100 $\mathrm{j} / \mathrm{cm})$ and for below knee segment $(80 \mathrm{j} / \mathrm{cm})$ and one of the two patients with preoperative GSV diameter $>8 \mathrm{~mm}$ developed recurrence in our study, we suggest that large GSV diameter could play a role in recanalization rates after EVLA although it was not confirmed in our study.
On assessing the BMI of patients in our study, it was found to be independent variable for recurrence and has fair to good predictive value for recurrence after EVLA with cutoff $>30.5 \mathrm{~kg} / \mathrm{m} 2$. In comparison of this significant statistical finding in our study to previous studies, there was disagreement about the influence of high body mass (described as 'obese with a large adipose thigh and leg) on using endothermal ablation. This divided opinion reflects the evidence, which provides no strong data. A retrospective cohort study by Merchant and Pichot documented an association between high body mass index (BMI) and recurrence after five years. The mechanism by which a high BMI results in anatomical failure remains unclear. However, patients with high BMI values tend to pose more procedural challenges such as inadequate compression and incomplete removal of varicose veins that result in incomplete relief of venous hypertension ${ }^{[15]}$. Fernández et al also found $\mathrm{BMI}>30 \mathrm{~kg} / \mathrm{m} 2$ was independent risk factor for recanalization and proposed that fibrosis caused by the EVLT was overcome by increased femoral venous pressure, with the saphenous vein reopening in a proximal to distal fashion, sometimes into a varicose tributary close to the SFJ that functions similarly to a relief valve ${ }^{[16]}$. Timperman has also found that obesity was common among patients in whom recanalization occurred due to increase abdominal and femoral venous pressure ${ }^{[19]}$. On the other hand, Theivacumar et al., reported no influence of BMI on early truncal occlusion rates after laser ablation ${ }^{[7]}$. Further analysis of 15 trials by Van der Velden et al showed that BMI was not a predictor of truncal ablation at one year: however, only $8.7 \%$ of the patients with a BMI $>30 \mathrm{~kg} / \mathrm{m}^{2}$ were included and this might have caused underestimation of the influence of BMI on recanalization ${ }^{[8]}$.

In our study both AASV and postoperative perforators were observed in $77.8 \%$, partial GSV recanalization in $66.7 \%$ 
and non-truncal varicosities in $55.6 \%$ of recurrent patients. Clinical symptoms and signs remained stable in recurrent patients during first 6 months even in the presence of AASV and incompetent perforators in 7 of 9 patients. After 12 months patients with AASV began to deteriorate in their clinical scores which were considered the median time to recurrence, however, the median time to recurrence was not determined in recurrent patients with postoperative incompetent perforators. Those results were compared to a study by Merchant and Pichot which showed that reflux in AASV occurred in $17.8 \%$ of recurrent limbs while recanalization of GSV occurred in $69.7 \%$ of recurrent limbs mostly related to either a refluxing tributary or an incompetent thigh perforator. This study concluded that ablation of AASV and incompetent thigh perforator could increase the long-term durability of the procedure ${ }^{[15]}$.Another study by Rasmussen et al. which showed that recurrence following EVLA at five years was predominantly due to reflux in the AASV and recanalization of the previously treated GSV ${ }^{[20]}$.

In the Recurrent Veins After Thermal Ablation (REVATA) study, with a median follow-up of 3 years, demonstrated that recanalization of the GSV occurred in $29 \%$ of limbs, but "perforator pathology" was found in 64\%. New AAGSV reflux was responsible for $40 \%$ of those patients who developed recurrent venous disease ${ }^{[21]}$. The REVATA study assumes that the etiology of incompetent perforators after ablation may be the result of "arterialization." This phenomenon may be related to thermal injury, since the US findings are near the thermally treated saphenous vein. Flow with increased pressure in refluxing perforators contributed to GSV recanalization ${ }^{[21]}$. Moreover, a true relationship between recurrent GSV insufficiency and incompetent postoperative calf perforators was documented in the REVATA study and concluded that GSV ablation should begin at midcalf level below these perforators to reduce the chance of future new insufficiency in untreated segments in addition to ablation of calf perforators ${ }^{[21]}$. One possible explanation to new AASV insufficiency is that once the GSV is ablated, flow is then directed to the AASV. Due to inherent defects in vein wall or valves, resultant insufficiency occurs. Prior to GSV ablation, refluxing flow mainly follows the larger diameter GSV ${ }^{[21]}$. A study by Winokur et al., showed that most cases of recurrence occurred due to recanalization of a segment of a previously treated vein with recurrent reflux or new reflux in the anterior accessory saphenous vein and not due to incompetent perforator ${ }^{[22]}$. This reinforces our findings that preoperative patent AASV and postoperative incompetent perforators could play a major role in prediction of recurrence through new retrograde flow in AASV after GSV ablation and enlargement of calf and thigh perforators "arterialization" mainly which enhances GSV recanalization rates and new GSV reflux. The presence of AASV and postoperative incompetent thigh and calf perforators in addition to BMI $>30$ $\mathrm{kg} / \mathrm{m}^{2}$ are major determinants of recurrence after EVLA and are documented in the most previous studies. It is not clear if patent refluxing AASV and incompetent perforators affected a certain pattern of recurrence (partial recanalization and non-truncal varicosities) as they occurred nearly at the same percentage in both pattern types in our study. Several explanations were mentioned to justify this correlation with no confirmatory data in previous studies.

Moreover, our study did not address the role of SSV incompetency in recurrence due to lack of cases as well as the amount of energy and the speed of pullback due to standardization of high energy and constant pullback for all patients.

\section{Conclusion:}

Our study focused on major determinants of recurrence rates and found a correlation between BMI, postoperative 
incompetent perforators and pre-operative patent AASV and recurrence rates during midterm follow-up. Those findings were comparable to the previous literature: however, GSV diameter was found to be statistically insignificant compared to other studies. Other variables like age and gender were not established as predictors of recurrence. As a result, further studies are needed to prove the relationship of those determinants to recurrence rates.

\section{Conflict of Interests}

The authors declare that there is no conflict of interests regarding the publication of this paper.

\section{REFERENCES:}

1. Rabe E, Guex JJ, Puskas A, Scuderi A, Fernandez Quesada F. VCP Coordinators. Epidemiology of chronic venous disorders in geographically diverse populations: results from the Vein Consult Program. Int Angiol 2012; 31(2):105e15.

2. Callam MJ. Epidemiology of varicose veins. BrJ Surg. 1994; 81:167-173.

3. Boné C. Tratamientoendoluminal de lasvarices con laser de diodo:studio prelimino. Rev PatolVasc, 1999; 5:35-46.

4. Min R, Zimmet $S$, Isaacs $M$, Forrestal $M$. Endovenous laser treatment of the incompetent greater saphenous vein. J Vasc Interv Radiol 2011; 12:1167-1171.

5. Babilas P, et al: Selective photothermolysis of blood vessels followingflashlamp-pumped pulsed dye laser irradiation: in vivo results andmathematical modeling is in agreement. J Invest Dermatol125:343-352, 2005

6. Nicolaides A, Kakkos S, Eklof B, Perrin M, Nelzen $\mathrm{O}$, Neglen $\mathrm{P}$, et al. Management of chronic venous disorders of the lower limbs guidelines according to scientific evidence. Int Angiol 2014; 33:87e208

7. Theivacumar NS, Darwood R, Gough MJ. Neovascularisation and recurrence 2 years after varicose vein treatment for sapheno-femoral and great saphenous vein reflux: a comparison of surgery and endovenous laser ablation. Eur J Vasc Endovasc Surg. 2009; 38:203-207.

8. Van der Velden SK, Lawaetz M, De Maeseneer MG, et al. Predictors of recanalization of the great saphenous vein in randomized controlled trials 1 year after endovenous thermal ablation. Eur J Vasc Endovasc Surg. 2016; 52:234-241.

9. Kundu S, Lurie F, Milliard SF, Padberg F, Vedantham S, Elias S, et al. Recommended reporting standards for endovenous ablation for the treatment of venous insufficiency: joint statement of the American Venous Forum and the Society of Interventional Radiology. J Vasc Surg 2007; 46:582-9.

10. Porter JM, Moneta GL. An International Consensus Committee on Chronic Venous Disease. Reporting standards in venous disease: an update. J Vasc Surg. 1995; 21:635-645.

11. Perrin M, Dedieu F, Jessent V, Blanc M. Evaluation of the new severity scoring system in chronic venous disease of the lower limbs: an observational study conducted by French angiologists. Phlebolymphology. 2006; 13:6-16.

12. Bradbury AW, Stonebridge PA, Callam MJ, Walker AJ, Allan PL, Beggs I, et al. Recurrent varicose veins: assessment of the saphenofemoral junction. Br J Surg 2004; 81:373e5.

13. Van den Bos R, Arends L, Kockaert M, Neumann M, Nijsten T. Endovenous therapies of lower extremity varicosities: A meta-analysis. J Vasc Surg. 2009;49(1): 230239.

14. Wallace T, El-Sheikha J, Nandhra S, et al. Long-term outcomes of endovenous laser ablation and conventional surgery for great saphenous varicose veins. Br J Surg 2018; 105: 1759-1767.

15. Merchant RF, Pichot O. Long-term outcomes of endovenous obliteration of saphenous reflux as a treatment for superficial venous insufficiency. J Vasc Surg 2005; 42:502-9; discussion: 509.

16. Fernandez CF, Roizental M, Carvallo J. Combined endovenous laser therapy and 
microphlebectomy in the treatment of varicose veins: efficacy and complications of a large single center experience. J Vasc Surg 2008; 48:947e52.

17. Kemaloğlu C. Saphenous vein diameter is a single risk factor for early recanalization after endothermal ablation of incompetent great saphenous vein. Vascular. 2019; 27(5):537-541

18. Desmyttere J, Grard C, Wassmer B, Mordon S. Endovenous 980-nm laser treatment of saphenous veins in a series of 500 patients. J Vasc Surg 2007; 46:1242e7.

19. Timperman P.E. Prospective evaluation of higher energy great saphenous vein endovenous laser treatment. J Vasc Interv Radiol, 2005; 16: pp. 791-794.
20. Rasmussen L, Lawaetz M, Bjoern L, Blemings A, Eklof B. Randomized clinical trial comparing endovenous laser ablation and stripping of the great saphenous vein with clinical and duplex outcome after 5 years. J Vasc Surg 2013; 58(2):421e6.

21. Bush RG, Bush P, Flanagan J, Fritz R, Gueldner T, Koziarski J, et al. Factors associated with recurrence of varicose veins after thermal ablation: results of the recurrent veins after thermal ablation study. Scientific World Journal 2014; 2014:505843.

22. Winokur $\mathrm{R}$, Khilnani $\mathrm{N}$ and Min $\mathrm{R}$. Recurrence patterns after endovenous laser treatment of saphenous vein reflux. Phlebology, 2015; 0(0) 1-5. 
العوامل المؤثرة لمعدل التكرار أثناء متابعة متوسطة المدي لمرضى الدوالي الأولية بعد عملية استئصال

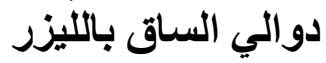

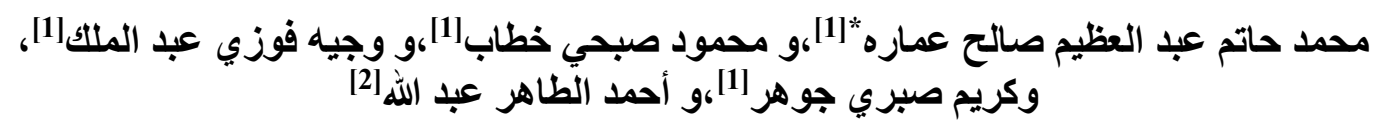

خلفية: كان الهدف من هذه الدراسة الأثر ابية المستبقة تحديد العو امل الهذتلفة التي تؤثر على معدلات تكرار الإصابة

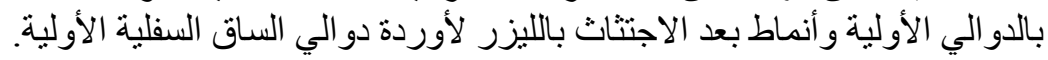

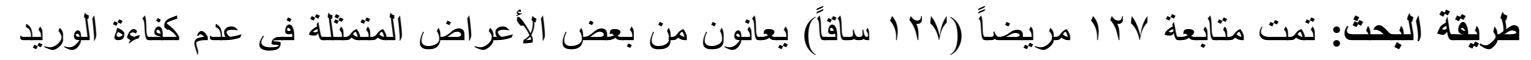

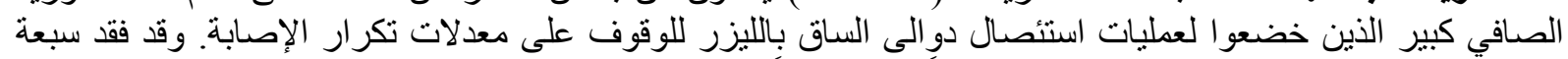

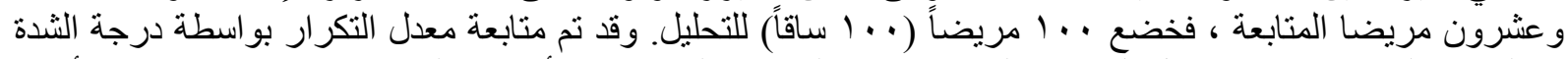

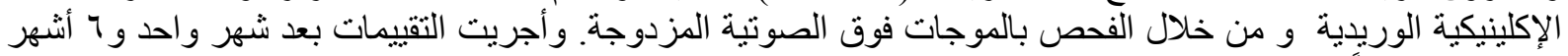

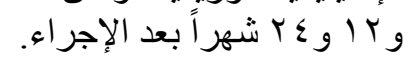

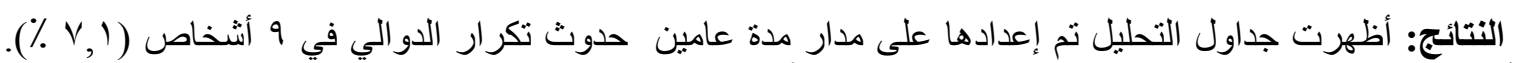

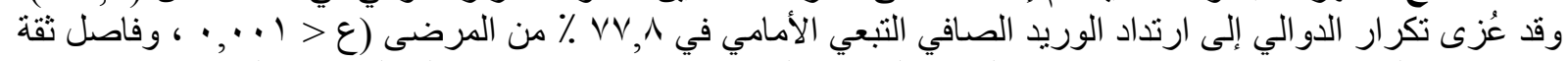

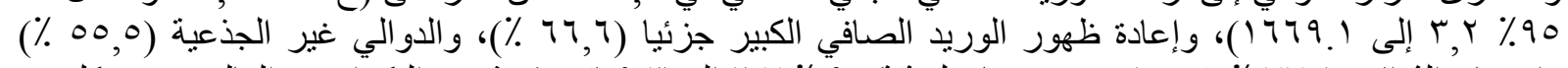

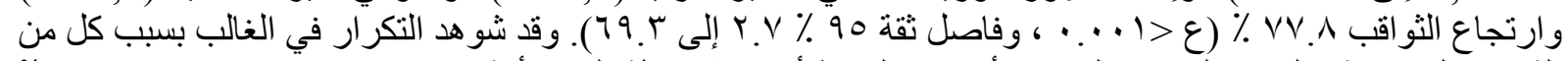

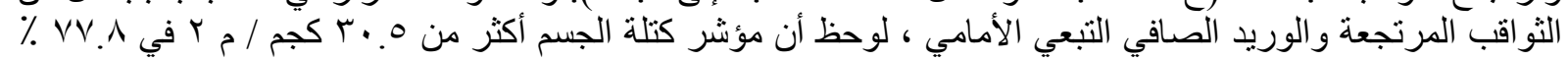

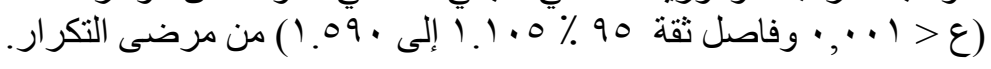

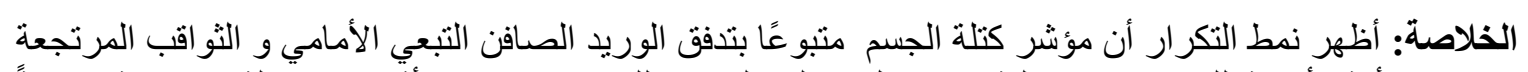

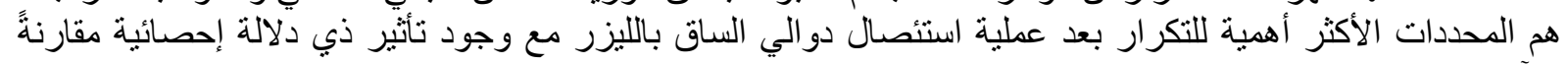
بالآخرين. 